\title{
Cuing effects in short-term recall
}

\author{
GERALD TEHAN \\ University of Southerm Queensland, Toowoomba, Queensland, Australia \\ and \\ MICHAEL S. HUMPHREYS \\ University of Queensland, St. Lucia, Queensland, Australia
}

\begin{abstract}
Past research indicates that short-term memory can be immune to the effects of proactive interference (PI). Past research also indicates that immunity to PI is found only in those circumstances where phonemic representations of to-be-remembered items are present and provide discriminative information. The first three experiments demonstrate the existence of a further boundary condition. PI is observed only if interfering and target items are subsumed by the same cue. This finding suggests that short-term recall, like long-term recall, is cue dependent. Cuing effects are further explored in two experiments that manipulate category dominance. The finding that category dominance effects parallel PI effects strongly suggests that retrieval cues play a critical role in short-term recall.
\end{abstract}

Short-term episodic memory performance differs from long-term performance in a number of ways. Capacity limitations appear to differ, rapid forgetting is observed in the short-term domain, and phonemic information appears to be more prominent over short retention intervals. Recently, it has become apparent that immunity to proactive interference (PI) can be added to this list. The empirical finding that immediate memory for span-length lists is not influenced by prior experience with similar materials serves as our operational definition of immunity to PI. While immunity to PI has not been as extensively studied as some of the other characteristics, it appears to be equally robust in that it is observed in short-term recognition (Halford, Maybery, \& Bain, 1988; Wickens, Moody, \& Dow, 1981), short-term serial recall (Humphreys \& Tehan, 1992; Tehan \& Humphreys, 1995), and short-term cued recall tasks (Tehan \& Humphreys, 1995). While some explanations have identified storage in primary memory as the causal mechanism in producing immunity to PI (Halford et al., 1988; Wickens et al., 1981), Tehan and Humphreys (1995) have attributed the cause to the presence of transient phonemic codes. This assertion is based upon the finding that immunity to $\mathrm{PI}$ is sensitive to manipulations that weaken or strengthen phonemic codes. In the present article, we wish to demonstrate that there is a further boundary condition to observing PI in short-term memory. We first aim to show that short-term PI effects, irrespective of the codes available, are cue dependent. Sec-

This research was supported by Australian Research Council Grant A79531860. Several of the experiments reported here are part of the first author's doctoral dissertation at the University of Queensland. The authors would like to thank Michael Masson, James Nairne, and Robert Greene for helpful comments upon an earlier draft of this manuscript. Correspondence should be addressed to G. Tehan, Department of Psychology, University of Southern Queensland, Toowoomba, Q4350, Australia (e-mail: tehan@usq.edu.au). ond, we seek to explore the generality of the coding and cuing factors that influence PI with reference to a second cuing phenomenon-that of category dominance.

\section{Immunity to $\mathbf{P I}$}

The role of PI in short-term retention tasks is well established, particularly with respect to the Brown-Peterson distractor task (Brown, 1958; Peterson \& Peterson, 1959). Keppel and Underwood (1962) found that very little forgetting was observed on the first trial in the BrownPeterson task irrespective of retention interval and that the traditional forgetting curve associated with this task emerged gradually over the three or four following trials. These findings strongly implicated PI as the causal mechanism for Brown-Peterson forgetting. The work of Wickens and his colleagues with the release-from-PI paradigm, of which more will be said later, confirmed the importance of PI in this task (Wickens, 1972; Wickens, Born, \& Allen, 1963).

The influence of PI, however, is attenuated under some conditions. For example, Wickens et al. (1981) demonstrated that performance on an immediate recognition test of a subspan list of taxonomically related items was uninfluenced by previous study of similar lists. That is, it was immune to the effects of PI. This was not the case on a delayed test where PI effects were readily apparent. Halford et al. (1988), using the same task as Wickens et al., demonstrated that PI was observed even on an immediate test if the number of items to be remembered was above span. The conclusion that immunity to PI would be observed only on an immediate test of subspan lists has also been confirmed using serial recall tasks (Dempster \& Cooney, 1982; Humphreys \& Tehan, 1992).

The apparent relationship between immunity to PI and span led Tehan and Humphreys (1995) to suppose that some mechanism or process that was involved in span might also be responsible for producing immunity to PI. 
They chose to focus upon coding aspects of short-term memory performance. They first demonstrated that for serial recall of a four-item list, PI and phonemic similarity effects covaried inversely across a 2 -sec retention interval. That is, on an immediate test, phonemic similarity effects were present, but PI effects were not. However, on a delayed test phonemic, similarity effects were attenuated, but PI effects emerged. They then used a short-term cued recall task and found that immediate test performance was immune to PI only if the target and interfering items did not rhyme. If the list contained an interfering foil that rhymed with the target item, then PI was observed, irrespective of the type of cue used. Furthermore, PI was always observed, again irrespective of the type of cue used, when recall was delayed through $2 \mathrm{sec}$ of verbal shadowing. On the basis of the assumptions that in any short-term memory task multiple codes contribute to short-term performance (Crowder, 1989; Nairne, 1990) and that phonemic codes are very susceptible to retroactive interference (Conrad, 1967; Estes, 1973; Nairne, 1988, 1990; Tell, 1972), the Tehan and Humphreys explanation for immunity to PI was couched in terms of the presence of discriminative phonemic information for the target item that would allow that item to be easily discriminated from the interfering foil. In the case of rhyming items or, more generally, phonemically similar items, the presence of a phonemic representation of the target would not discriminate between target and foil. On a delayed test, they assumed that the phonemic code for the target would no longer be available due to retroactive interference, and, hence, discriminating the target from the foil would be more difficult.

The Tehan and Humphreys explanation focuses primarily upon the coding aspects of short-term PI. There is, however, evidence to suggest that cuing aspects of memory also are a strong determinant of PI. It is to this issue that we now turn.

\section{PI as a Cuing Effect}

We have stated elsewhere (Humphreys \& Tehan, 1992) that our preferred explanation of PI is a cuing explanation, although we acknowledge that this position is not universally accepted. At the theoretical level, cuing approaches to memory have enjoyed considerable general success. This success extends to explanations of PI in that O. C. Watkins and M. J. Watkins (1975) have demonstrated that the cue overload principle - a principle that has been successfully employed as a unified interpretation of such diverse memory phenomena as the list length effect in free recall, the advantage of categorized lists, subjective organization, the effects of extralist cuing, and part-set cuing effects (M. J. Watkins, 1981) - can also account for the build up and release from PI.

At the empirical level, there is also substantial support for a cuing explanation of PI. Much of this support is based upon the release-from-PI paradigm. In this paradigm, subjects receive a number of Brown-Peterson trials in which the materials come from a single category (e.g., "animals"). In this situation, performance gener- ally deteriorates across trials. If the materials change on any subsequent trial (e.g., "flowers"), performance returns to near original levels of performance. This increase in performance with a change in materials has been termed release from PI (Wickens et al., 1963). With regard to the cuing issue, Gardiner, Craik, and Birtwistle (1972) varied the standard release-from-PI paradigm by switching subsets of more general categories on the build-up and release trials. For example, within the category of "flowers," they gave their subjects "garden flowers" on the build-up trials but switched to "wild flowers" on the release trials. Three groups of subjects were all given the general category label (e.g., "flowers") on the first of the build-up trials. On subsequent build-up trials, no cue was given. Prior to the release trial, one of the three groups was given a subset name of the category (e.g., "wild flowers") as the cue and substantial release from PI resulted. A second group was given the subset cue immediately after the release trial had been presented. This group, who could use only the subset label as a retrieval aide - unlike the first group, who could use the subset label to influence encoding-demonstrated an amount of release from PI that was equivalent to that demonstrated by the first group. The third group was not presented with any cue on the release trial and did not show any release from PI.

Dillon and Bittner (1975) replicated the Gardiner et al. study but added an extra experimental condition in which they presented the same subset materials on both buildup and release trials. More specifically, their subjects were given four trials that consisted of Eastern Canadian cities, with the general label "North American Cities" being presented at the first trial. Again, at the fourth trial, some of the subjects were given the subset label "Eastern Canadian Cities." As was the case with the Gardiner et al. findings, providing the subset cue produced substantial release from PI. Furthermore, it did not seem to matter whether the subset cue was given at study or at test. The importance of this latter finding is that it not only supports a cuing explanation for PI but it seriously questions a simple trace-discrimination explanation of release from PI. The trace-discrimination hypothesis suggests that release from PI can be attributed to the fact that a change in materials on a release trial makes it easier for the subject to discriminate the most recent trace from earlier traces. In the Dillon and Bittner study, where there was no change of materials on the release trial, the provision of the subset cue could not have improved discrimination; however, release from PI was found. The fact that a subset cue provided after the release trial produced as much release from PI as when the cue was presented before the trial is taken as strong evidence for the cuing explanation. The primary conclusion of the Gardiner et al. and the Dillon and Bittner studies is that PI critically depends upon the retrieval cues used.

The above findings provide strong support of a cuing account of PI. In extending these findings to the short-term PI effects that Tehan and Humphreys have examined, we believe that a complete account must emphasize the role of category-specific retrieval cues. Thus, the logic behind 
the first three experiments was to take experimental conditions that are known to produce PI but to vary the retrieval cues in such a way that a cue would no longer subsume both target and interfering items. We expected that the change of cues would result in the absence of any sign of PI. To foreshadow the results of our experiments, PI effects depend critically upon the retrieval cue used. Interference will occur only if the retrieval cue subsumes both the target and interfering item. In the final two experiments, we explored category dominance effects as a second cuing phenomenon. In demonstrating that category dominance effects parallel PI effects, we argue that any model of short-term recall must involve both cuing and short-term coding processes.

\section{EXPERIMENT 1}

The rationale for Experiment 1 was to take a situation that is known to produce PI and to vary the retrieval cue. Tehan and Humphreys (1995) were able to show that PI occurred on a cued recall test when a taxonomic or ending category cue subsumed both the target item and an interfering foil. In the present experiment, subjects studied the same type of trial, but serial recall of the four most recent items (which contained a target item) was requested instead of cued recall for a single item among the four. There were two important considerations to this experiment. The first was to determine the extent to which category specific interference can be observed in serial recall.

The empirical base for PI in immediate serial recall where all of the items in a list are related is not large. Humphreys and Tehan (1992) examined PI effects in serial recall in which the materials were five-item blocks of either digits or blocks of letters. They replicated previous research in observing immunity to PI on an immediate test. That is, recall of the most recent block of digits was the same regardless of whether the previous blocks had contained digits or letters. However, after a very brief retention interval of approximately $2 \mathrm{sec}$, the effects of PI became evident. That is, recall was better when the earlier block consisted of letters than when it consisted of digits. Similarly, Tehan and Humphreys (1995) examined serial recall for a four-item list in which all the items within the list came from the same taxonomic category. PI was manipulated by presenting an earlier to-be-forgotten block in which the items came from either the same category as or a different category from that used in the second block. Again, the material in the first block had no influence on immediate serial recall; however, after $2 \mathrm{sec}$ of distractor activity, the material in the first block did assert an influence, in that PI emerged. In sum, it is apparent that category-specific PI can be observed in serial recall, but only after a brief retention interval. ${ }^{\prime}$

The second important consideration involves PI effects when the items within a four-item block are unrelated but an item in Block 2 is a member of the same taxonomic category as an item in Block 1 . When a taxonomic cue that subsumes both the Block 2 target and Block 1 foil is provided, Tehan and Humphreys (1995) have shown that PI depends upon the phonemic characteristics of target and interfering items. If the items do not rhyme, then immediate test performance is immune to PI. However, if the items rhyme or if a delayed test is employed, PI readily becomes apparent.

In short, we know that category-specific PI can be observed in serial recall when all the items in the list are related. We also know that category-specific PI can be observed in short-term cued recall where the to-beremembered items are unrelated but a to-be-forgotten foil is presented in an earlier block. The question we address is, to what extent PI will be observed when serial recall is required under the latter conditions? To do this, we have taken the cued recall lists but requested serial recall of the most recent block instead of cued recall. We assumed that category-specific information would not be all that useful in a situation where, by and large, all items within a trial come from different categories. Given that category membership is not obvious and that serial recall is required, we expected that PI effects should not be evident on either an immediate or a delayed test for either taxonomic or rhyme categories. That is, if categoryspecific PI is cue dependent, PI should not be observed if the category cue is not being used in any way.

In saying that category-specific information is not likely to be used in the present task, we have not addressed the issue of what cues are likely to be used. When it comes to serial recall, there are two broad approaches to the way in which serial order is maintained. The first approach is a chaining approach where the recall of one item serves as a cue for the recall of the following item. Chaining approaches of one type or another have appeared in many recent models of short-term memory performance (Jones, 1993; Lewandowsky \& Murdock, 1989; Shiffrin \& Cook, 1978). The alternative approach utilizes something akin to position cues (Estes, 1972; Johnson, 1991; Lee \& Estes, 1977). Our preference is for the latter of these two approaches and is based on the demonstration that repeating an item in the same serial position across successive lists in immediate serial recall produces more positive transfer than does repeating adjacent items across successive lists but in different serial positions (McNicol, 1978). In other words, repeated position cues produce more facilitation than do repeated chaining cues. Furthermore, Estes (1991) has demonstrated that, in serial recall, intrusions from immediately preceding trials (trial $n-1$ ) tend to intrude into the same serial positions on the subsequent trial (trial $n$ ) that they occupied in the original trial (trial $n-1$ ). That is, there appears to be cross talk between equivalent serial positions across lists. The Estes data provide a bench mark in the present experiment. If it is true that subjects use position cues, we might expect to see cross talk between Block 1 and Block 2. Thus, if there are any Block 1 intrusions, we would expect that they should intrude at greater than chance levels into the same serial position in Block 2 that they held in Block 1.

In short, we are making the assumption that, in serial recall, taxonomic category cues are not utilized, but serial position cues are. Consequently, the expectation is that 
category-specific PI will not be observed in the experiment, but position-specific PI will be.

\section{Method}

The basic structure of the critical trials used in the first three experiments is presented in Figure 1. Each trial involved memory for a four-item block, and each trial had either one or two such blocks. Category-specific PI was manipulated in the two-block trials in that, on an interference trial, an interfering foil from the same category as the target item was presented in the first block among three unrelated filler items. The target item also appeared among three filler items in the second block. On control (or no-interference) trials, a target item was presented in the second block with no related item in the first block. Directed forgetting instructions stressed that the subjects were always responsible for remembering the most recent block of four items.

Procedure. At the beginning of the experiment, the subjects were informed that they would be studying a series of one-block and two-block trials in which a block consisted of four words. However, it was also stressed that, at any one point in time, they only had to remember that most recent block of four items. Consequently, if the trial was a two-block trial, and this was signified by the presence of an exclamation mark (!) as the block separator, they were to forget the first block and concentrate on remembering the second block because it would be on this block that they would be tested. They were told that one-block and two-block trials would be randomly interspersed throughout the experiment and that since they would not know in advance what type of trial it was, it was in their best interests to treat each trial as a one-block trial until they learned otherwise.

Each trial began with a READY sign displayed on the computer monitor for $2 \mathrm{sec}$. The study items were then displayed individually at a rate of one word per second, and the subjects were instructed to remain silent throughout the presentation of the study items. On two-block trials, the block separator(!) was presented for I sec after the fourth word in the first block and before the first word in the second block. On an immediate test, the cue RECALL appeared immediately after the fourth item in the block. At this point, the subjects attempted to recall the items from the most recent block in serial order, with the instructions that they were to substitute the word something for any word that they had forgotten. On the delayed trials, two four-digit strings appeared on the screen after the fourth word, at the rate of one string per second. The subjects were required to read the digits aloud as they appeared on the screen. The recall cue appeared after this $2 \mathrm{sec}$ of shadowing activity. The subjects had $5 \mathrm{sec}$ to make a response before the next trial began. The experimenter recorded the subject's responses (correct recall, order errors, intrusion errors, omissions, etc.) on a hard copy of the subject's input file.

Materials. As mentioned earlier, the critical two-block interference trials contained two items from the same category placed among unrelated filler items. For half of the subjects, these items came from taxonomic categories; for the other half of the subjects, the items came from rhyme categories. These items have been derived by sampling two instances from each of a number of categories selected primarily from the rhyme category norms (Walling, McEvoy, Oth, \& Nelson, 1984) and the taxonomic category norms (McEvoy \& Nelson, 1982) generated by Nelson and his colleagues at the University of South Florida. Since interpretation of the results of the present experiments depend in part upon equivalence of materials, Table 1 presents the cuing characteristics of these items.

The interfering foil in Block 1 was the high-dominant instance of the category and the Block 2 target was the relatively weak member of the category. In Table 1, two different measures of category dom. inance are presented. The strength measure reflects the percentage of subjects who produced this response in the controlled association task. The other measure reflects the ranking of the frequency of the response. Thus, a ranking of 1 indicates that this response was the

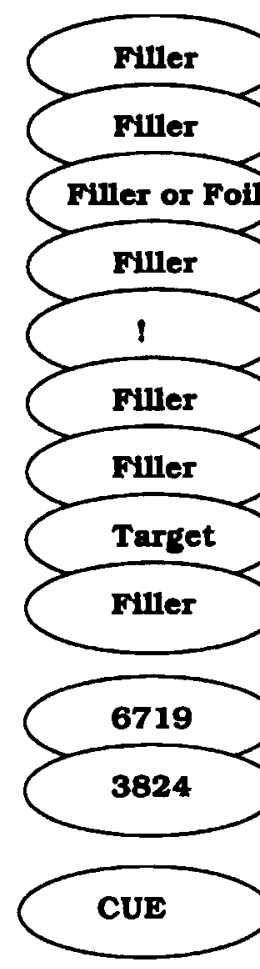

$\begin{array}{ccc}\begin{array}{c}\text { Experiment } \\ 1\end{array} & \begin{array}{c}\text { Experiment } \\ 2\end{array} & \begin{array}{c}\text { Experiment } \\ 3\end{array} \\ \text { jail } & \text { jail } & \text { jail } \\ \text { silk } & \text { silk } & \text { silk } \\ \text { dog } & \text { orange } & \text { wrench } \\ \text { peach } & \text { peach } & \text { peach } \\ ! & ! & ! \\ \text { page } & \text { page } & \text { page } \\ \text { leap } & \text { leap } & \text { leap } \\ \text { cat } & \text { carrot } & \text { bench } \\ \text { witch } & \text { witch } & \text { witch } \\ & & \\ \text { 6719 } & 6719 & 6719 \\ 3824 & 3824 & 3824 \\ & & \\ \text { RECALL } & \text { VEGETABLE } & \text { BEN_ }\end{array}$

Figure 1. Structure of the two-block trials in Experiments 1, 2, and 3. 
Table 1

Characteristics of Materials Used in Experiments 1, 3, 4, and 5

\begin{tabular}{lcc}
\hline List Item & $\begin{array}{c}\text { Dominance } \\
\text { Strength (\%) }\end{array}$ & $\begin{array}{c}\text { Output } \\
\text { Rank }\end{array}$ \\
\hline $\begin{array}{c}\text { Taxonomic Categories } \\
\text { Interfering foil (Exp. 1)/high dominance } \\
\text { (Exp. 4) }\end{array}$ & 37 & 1.3 \\
$\begin{array}{c}\text { Target (Exp. 1)/low dominance (Exp. 4) } \\
\text { Rhyme Categories }\end{array}$ & 1.5 & 12.4 \\
$\begin{array}{c}\text { Interfering foil (Exps. 1, 3)/high dominance } \\
\text { (Exp. 5) }\end{array}$ & 30 & 1.6 \\
Target (Exps. 1, 3)/low dominance (Exp. 5) & 2.5 & 9.2 \\
\hline
\end{tabular}

most frequently given response, whereas a ranking of 9 would indicate that there were eight more frequently produced responses than the one selected. It would appear that the differences between the cuing aspects of the materials from taxonomic categories and the rhyming categories are minimal. Within each class, the targets and foils were similar to each other in that they were concrete nouns that were matched for word frequency. The only difference between the different classes was that overall average word frequency for the items from rhyming categories (43.9; Kučera \& Francis, 1969) was higher than that of taxonomic categories (27.7). In short, the materials from rhyming and taxonomic categories are similar in most important respects. To the extent that word frequency influences short-term cued recall, one might expect better recall with the rhyme categories than with the taxonomic categories.

In creating the trials, for each subject, separate word pools were first generated for filler and target items. The characteristics of the critical items have been described above. The filler items were similar to the critical items, with the exception that there was no category overlap between filler and experimental items. To create the critical two-block trials, the target and foil were first randomly as signed to the various experimental conditions. The target and foil were then embedded among randomly selected filler items, such that two four-item blocks were created. In the case of control (or nointerference) trials, the interfering foil was replaced by a filler item, such that the target was the only instance of the category in the list. On the interference trials, foil and target always appeared in the same serial position (on half the trials, Position 2; the other half Position 3 ) in their respective blocks. ${ }^{2}$

In the condition in which taxonomic categories were used, the subjects studied 48 critical two-block trials; in the condition in which rhyming categories were used, there were 60 two-block trials. For both sets of materials, there were twice as many interference trials as control trials. The reasons for this had to do with variables that were of interest in the Tehan and Humphreys (1995) experiments but are not crucial for present purposes. For each type of trial, half the trials were tested immediately after the second block had been presented and half were tested after a 2 -sec filled retention interval.

A number of one-block trials were also tested for serial order. These trials were included primarily to ensure that the subjects attended to the first block in a two-block trial. Generally speaking, performance on these trials indicated that they served their purpose, and, as such, they are not considered any further in any of the analyses.

The order of the filler and experimental trials was randomized for each subject. This ensured that the subjects never knew in advance whether the trial would be a one-block filler trial or a twoblock interference or control trial.

Subjects. Forty subjects participated in this experiment. Twenty served in the condition where serial recall of trials in which interfering and target items came from taxonomic categories was required, and 20 served in the condition where interfering and target items came from rhyme categories.

\section{Results}

Category-specific PI. The serial recall data are presented in Table 2 and represent the likelihood that the critical item in the second block has been recalled in its correct serial position. Recall of the target item out of position was also examined. Since the results paralleled the serial position data, the out-of-position scores are ignored.

The serial recall data were analyzed using two $2 \times 2$ (retention interval $\times$ interference) repeated measures analyses of variance (ANOVAs). For both taxonomic and rhyme categories, the effects of retention interval were readily apparent $\left[F(1,19)=127.33, M S_{\mathrm{e}}=0.04\right.$, and $F(1,19)=254.84, M S_{\mathrm{e}}=0.019$, respectively]. The interfering foil in Block 1 did not appear to influence performance for either class, nor did it interact with retention interval. These comparisons are based upon an alpha level of .05, as are all subsequent comparisons.

Subsidiary analyses indicated that, on immediate tests, there was no evidence that the presence of an interfering item from the same category as the target item had any effect upon recall of the target item for taxonomic materials $\left[F(1,19)=0.44, M S_{\mathrm{e}}=0.014\right]$ or rhyme categories $\left[F(1,19)=0.12, M S_{\mathrm{e}}=0.019\right]$. Likewise, on the delayed tests, the interfering item had no effect upon serial recall of the target item for taxonomic categories $[F(1,19)=$ $\left.0.61, M S_{\mathrm{e}}=0.016\right]$ or rhyme categories $[F(1,19)=1.09$, $\left.M S_{\mathrm{e}}=0.008\right]$. In this and the following experiments, we obtained estimates of effect size in order to test the strength of any observed difference. Effect size was calculated by dividing the difference between treatment means by a pooled estimate of the population standard deviation. In the present experiment, the effect size of category-specific PI was very weak in all cases.

Position-specific PI. The subjects were able to discriminate the second block from the first in that Block 1 intrusions from any serial position were fairly rare, with

Table 2

Mean Probability of Recalling the Target Item as a Function of Proactive Interference, Type of Test, and Retention Interval

$\frac{\text { Retention Interval }}{\text { Immediate }}$ Delaved

Experiment 1 (Serial Recall)

Taxonomic Materials

No interference $\quad .78 \quad .26$

Interference

Rhyme Categories

No interference

Interference

$.81(.15)$

$.29(.17)$

81

.35

$.82(.08)$

$.32(.22)$

Experiment 2 (hydrogen zinc TYPE OF METAL)

No interference

Different category

.41

Same category

Experiment 3 (wrench bench BEN)

No interference .94 Interference $.91(.07)$ 89

Note-Numbers in parentheses reflect the effect size obtained for the comparison of the interference condition specified with the relevant nointerference condition. 
only 126 observed across all subjects in all conditions. Of these, 26 occurred on an immediate test and 100 were observed on a delayed test collapsed across serial position, interference condition, and type of material. However, on both immediate and delayed tests, the intruding item appeared in the same serial position at greater than chance levels, although this effect appeared to be stronger on an immediate test than on a delayed test. Thus, on an immediate test, the probability of the intruding item appearing in the same position was .54, and the probability of it appearing in any of the three remaining positions was .46 . On the delayed test, the equivalent probabilities were .39 and .61 , which are still above chance.

\section{Discussion}

The present results provide initial support for the importance of cues in producing PI. With regards to categoryspecific PI, subjects can study a list in which an interfering foil and a target item are presented, and, if a cue subsumes both items (as was the case with the Tehan and Humphreys cued recall experiments), then PI is observed. Likewise, if serial recall of categorized lists is requested, PI effects can also be observed (Humphreys \& Tehan, 1992; Tehan \& Humphreys, 1995). In both these instances, it would seem reasonable to assume that subjects are utilizing category labels as cues. If, however, the recall cue does not focus upon the relationship that exists between the target and the foil, as we assume happened with serial recall in the present experiment, then category-specific PI is not observed. Furthermore, if we assume that the subjects utilized serial position cues in the present task, then the pattern of Block 1 intrusion errors provides evidence for position-specific PI. Consequently, we tentatively interpret the results of Experiment 1 as an indication that PI effects are cue specific.

Our tentativeness is based upon the fact that cued recall and serial recall are quite distinct tasks, and, thus, task differences might provide possible grounds for alternative explanations. For example, PI effects might still occur in the present task, but these effects might be masked by other interference effects, such as output interference. Given the possibility of alternative explanations, the principle aim of Experiment 2 was to demonstrate more directly that the effects of PI critically depend upon the retrieval cue presented.

\section{EXPERIMENT 2}

Experiment 2 was based upon the Dillon and Bittner (1975) concept of equating encoding conditions and varying the retrieval cues presented. The experiment reverts back to a short-term cued recall task that involves three critical interference conditions. In the first interference condition (same-category interference), both interfering and target items are subsumed by the category cue (e.g., "orange" and "carrot" are both subsumed by the category label "TYPE OF JUICE"). In the second interference condi- tion (different-category interference), both interfering and target words are presented, but only the target item is subsumed by the category label (e.g., both "orange" and "carrot" are presented, but the cue is "VEGETABLE"). Both of these conditions are compared with a no-interference condition in which there is no interfering item presented in the first block.

Given conditions in which PI can be observed using nonrhyming taxonomic materials - that is, a delayed testthe predictions from a cuing perspective are straightforward. If the category cue subsumes both the interfering item and the target item, then PI will be observed. If, however, the cue subsumes only the target item, then PI will not be observed.

\section{Method}

Subjects. Twenty first-year psychology students from the University of Southern Queensland participated in this experiment for course credit.

Materials. In this experiment, there were 30 critical two-block trials of the type used in Experiment 1, which were all tested via delayed cued recall. Ten of the critical trials involved the standard interference condition in which two members of a category appeared among unrelated filler items on a trial, one as an interfering foil in the first block and the other as the target item in the second block. Another 10 trials involved the standard control trials in which the target alone was presented. The final 10 trials were similar in structure to the standard interference trials in that a potentially interfering item was present in the first block, and the target item was present in the second block. However, these trials differed in that the cue used at recall subsumed the target item but excluded the interfering foil.

In creating the critical materials for the above trials, 30 targets were generated that could be conceived as instances from multiple categories. For example, "carrot" is an instance of both vegetable and juice. An interfering foil for each of the categories was also selected such that this foil was not an instance of the second category. Thus, for example, "orange" is an instance of juice but not a vegetable. Likewise, "pumpkin" is a vegetable but not a juice.

In creating the trials for each subject in this experiment, the 30 targets were first randomly assigned to the three conditions. For the same-category interference trials, the interfering foil was an instance of the category cued. Which one of the two categories used on each was counterbalanced across subjects. Thus, half of the subjects studied trials in which "pumpkin, carrot, VEGETABLE" were the critical items, whereas another half studied "orange, carrot, TYPE OF JUICE" as the critical items. For the different-category interference trials, the interfering foil came from the category that was not cued. Which specific foil and which specific cue were utilized on each trial was again counterbalanced. Half of the subjects saw "pumpkin, carrot, TYPE OF JUICE," whereas the other half studied "orange, carrot, VEGETABLE." In the control condition, only the target appeared, and which cue was utilized on each trial was also counterbalanced across subjects.

In addition to the critical trials, there were 30 filler trials that were tested via serial recall. The 60 trials in the session were presented in a random order.

Procedure. The presentation conditions and the instructions given to the subjects were the same as those employed in Experiment 1 . The only deviation in procedure from Experiment 1 was that all of the two-block trials were delayed trials in which the subjects' recall was delayed by $2 \mathrm{sec}$ of verbal shadowing of visually presented digit strings and that cued recall was required instead of serial recall. Again, the category cue was presented for $2 \mathrm{sec}$, and the subjects had $5 \mathrm{sec}$ to respond. 


\section{Results}

A summary of performance on the cued recall trials is presented in Table 2. As is evident in the table, categoryspecific interference appears to be limited to the case where the two items are subsumed by the same cue.

The correct recall data were analyzed by two planned comparisons. To establish the presence of PI in the experiment, the first comparison compared the same-category interference condition with the no-interference condition. This comparison indicated reliable effects of PI $[F(1,19)=$ $\left.6.06, M S_{\mathrm{e}}=0.020\right]$. The second, and more important, comparison showed that there was no difference between the no-interference and different-category interference conditions $\left[F(1,19)=0.02, M S_{\mathrm{e}}=0.027\right]$. An examination of effect size confirmed that PI effects were very weak in the same-category condition (.09) but were stronger in the different-category condition (.53).

The list-intrusion data confirm that these differences were due to PI. Recall of the interfering foil represented a major source of error in the same-category condition (.24), but not in the different-category condition (.01).

\section{Discussion}

The present results are quite straightforward. When the retrieval cue subsumes the two items, then PI is observed; however, when the cue subsumes only the target item, PI is no longer evident. Given that encoding conditions have been held constant, the presence of PI in the same-category condition but not in the different-category condition indicates that PI effects are cue specific. Such a finding also supports the idea that the differences between cued recall and serial recall in Experiment 1 can be conceptualized as cuing effects.

In Experiment 3, we tested the generality of the present findings by utilizing items from rhyming categories. Using word endings as cues produces PI effects on both immediate and delayed cued recall tests (Tehan \& Humphreys, 1995, Experiment 4). Using the logic employed in Experiment 2, in the case where two rhyming items are present in the list, a stem cue (i.e., the first three letters in the word) should specify the target item alone. Consequently, the expectation would be that the differences that Tehan and Humphreys found between performance on interfering and control trials when ending cues were supplied would be eliminated if a stem cue was used instead.

\section{EXPERIMENT 3}

\footnotetext{
Method

Subjects. Twenty introductory psychology students from the University of Southern Queensland participated in the experiment.

Materials. The subjects studied 68 trials, consisting of 48 twoblock trials and 20 filler trials. For the two-block trials, half of the trials contained an interfering foil in the first block that rhymed with a target item in the second block (e.g., wrench, bench) and half contained the target item alone. The materials used in this experiment were the same as those used in the rhyme categories of Experiment 1 . For each type of trial, half of the trials were tested immediately after the second block had been presented and half were tested after a 2 -sec filled retention interval.
}

Procedure. The instructions and presentation conditions in Experiment 3 were the same as those used in Experiments 1 and 2. What is unique in the present experiment is that a stem cue was adopted. Thus, if the foil was "wrench" and the target word was "bench," the cue "BEN" was presented either immediately or after $2 \mathrm{sec}$ of distractor activity.

\section{Results}

Performance on the cued recall trials in Experiment 3 is presented in Table 2. Planned comparisons established that the presence of a similar-sounding item in the first block had no effect upon recall of the target item on both immediate tests $\left[F(1,19)=0.66, M S_{\mathrm{e}}=0.014\right]$ and delayed tests $\left[F(1,19)=0.75, M S_{\mathrm{e}}=0.008\right]$. Weak effect sizes ( .07 for immediate tests and .19 for delay tests) were also characteristic of the data. These results suggest that the PI effects found using instances from rhyming categories are cue specific in much the same way that semantic PI effects are cue specific.

One possible problem with the above results is that absolute levels of performance were quite high and that the lack of any difference may simply reflect ceiling effects. However, although performance was good, there was a significant effect of retention interval $[F(1,19)=4.53$, $\left.M S_{\mathrm{e}}=0.008\right]$. This indicates that, in the delayed condition, performance was off ceiling. The lack of interference effects in this condition cannot be attributed to ceiling effects.

\section{Discussion}

To summarize the data to this point, we have described the situations in which PI is and is not found in short-term recall. We have adopted a general methodology of maintaining the encoding conditions known to produce PI effects but have varied the retrieval cues. In Experiments 1 and 3 , we utilized encoding procedures that, in other circumstances, produce PI; however, by altering the retrieval demands, we demonstrated that PI effects do not emerge. In Experiment 2, we directly manipulated the retrieval demands and demonstrated that PI emerged only when the cue subsumed both the foil and the target. Thus, the results of the first three experiments tend to suggest that a necessary condition for PI to be observed in the short-term recall is that a retrieval cue must subsume both target and interfering items. It may be the case that a study trial will contain similar items, as in Experiments 1,2 , and 3, but similarity will not have any effect upon performance if an alternative retrieval cue focuses on some other attribute of the target word.

As indicated earlier, cuing explanations of PI are not universally accepted. The cuing account, however, could be strengthened if it could be demonstrated that the factors that influence short-term PI effects also moderate other, less controversial, cuing effects. Consequently, the remaining two experiments focus on the category dominance effect- that is, the finding that, in cued recall tasks, the dominant items in a category are better recalled than are weaker instances.

When a group of people are given a cue of some description and asked to respond with the first instance of the 
category that the cue specifies, invariably some responses are produced more frequently than others. Such procedures have been used to develop norms of associative strength for different classes of cues (e.g., taxonomic categories, word rhyme categories, word stem categories, word associates, ending fragments, etc.). In cued recall, the frequency with which a particular item is recalled is well predicted by the frequency with which the response is produced in the association task. In other words, the high-dominant instances in the category tend to be better recalled than do the low-dominant instances. The pervasiveness of the category dominance effect is such that cue-based models of retrieval-be they direct-access or generate-recognize models-make the assumption that cue-target strength is one of the prime determinants of successful recall.

Category dominance is, however, not the only determinant of cued recall. Nelson and McEvoy (1979) first demonstrated that the size of the category that was being cued was also an important predictor of successful recall. They found that a target item on a study list was less likely to be recalled if that item came from a large category (a category with many different instances) than if the item came from a small category. Nelson and Friedrich (1980) also demonstrated that when cue set size was controlled for, the associative set size of the target item influenced recall. Again, large associative sets tended to inhibit recall relative to small associative sets. These results imply that when retrieval is initiated, all instances of the category, including the target, are activated, as are all associates of the target. All of these activated items then served as a source of inhibition for the target item (Nelson, 1989). On the basis of these and similar results, Nelson, Schreiber, and McEvoy (1992) have suggested that cued recall performance is determined by the size of the category that is being cued, the associative set size of the target item, and cue-target strength.

Given these findings, we make the assumption that the factors that influence long-term cued recall also influence short-term cued recall. Thus, the first expectation is that cue-target strength effects will be evident in that highdominant instances of a category should be better recalled than should low-dominant instances. Second, although we do not directly test for cue set size or target set size, we assume that the preexperimental sources of competition that are evident on the long-term task are also present on a short-term cued recall task. That is, when the cue is presented on the short-term task, all of the items that are subsumed by that cue become competitors with the target item.

In making this assumption, the predictions concerning category dominance effects become very similar to those involving PI. In both cases, it is assumed that, at retrieval, the long-term representations of more than one item are activated. To the extent that transient phonemic codes play a role in producing immunity to PI, as Tehan and Humphreys (1995) have suggested, the presence of a phonemic code for the target item should provide a means of focusing in upon the target item. The only real difference between the PI and category dominance effects concerns the origin of the source of competition. With PI, that source is experimentally produced, whereas in a simple cued recall task where there is no interfering foil, the source is preexperimentally based. Experiments 4 and 5 set out to explore the potential similarity between PI and category dominance effects.

\section{EXPERIMENT 4}

In the following two experiments, the cued recall task that was used earlier was modified slightly. Instead of studying two-block trials, subjects now studied trials that consisted of a single six-item list. In all other respects, the task was similar, in that the target item on each list was embedded among five filler items, and memory for the target item was tested either immediately or after a 2 -sec filled retention interval.

In Experiment 4, category dominance effects were explored using taxonomic categories. If it is true that nontarget members of the category become competitors, the presence of phonemic codes for the target item should make it very distinctive and easily discriminable from all other competitors. Preexisting strength effects might thus be eliminated on an immediate test in much the same way that PI effects were eliminated. However, on a delayed test, it is expected that dominance effects will become evident when phonemic codes for the target item are no longer available.

We were still interested in the cuing aspects of this experiment by showing that category dominance effects depended upon the retrieval cue used. Consequently, one group of subjects in this experiment viewed a mixture of cued recall and serial recall trials, in which each trial had the same structure. Again, the expectation was that category dominance effects would be apparent upon cued recall trials, but not on serial recall trials where position cues would be used instead of taxonomic category cues.

\section{Method}

Subjects. Sixty subjects participated in the experiment. For 40 of the subjects, retention interval was a between-subjects variable, with cued recall and serial recall being varied within subjects. Thus, 20 of the subjects received immediate cued and serial recall tests and 20 received delayed tests. For the remaining 20 subjects, the critical trials were all cued recall trials, and retention interval was manipulated within subjects

Materials. The materials for this experiment were the same as those used in Experiment 1 - that is, a critical word pool consisting of two instances from each of 48 different taxonomic categories and a word pool of filler items that had no overlap in category membership with the critical items. The basic word pool of a high- and a low-dominant instance from each of 48 different taxonomic categories was divided into two subsets, each consisting of 24 highdominant words and 24 low-dominant words in order to counterbalance possible materials effects. The high-dominant instance in one set was replaced by the low-dominant instance in the second set, and vice versa.

In contrast to Experiments $1-3$, each of the 48 trials in the present experiment consisted of a single six-item list. On each trial, a single target word was embedded among five filler items. Twentyfour of the trials involved the high-dominant item, each of the six 
serial positions being sampled four times. Likewise, each serial position was sampled four times with low-dominant targets.

For two groups of subjects, half of the trials of each type were tested via cued recall and half via serial recall, with one group being tested immediately and one group being tested after a delay. This meant that each serial position was tested twice per condition. For example, a high-dominant target would have appeared in each serial position four times, twice being tested via serial recall and twice by cued recall. Similarly, a low-dominant item appeared four times, again being tested either by serial recall or cued recall on two occasions. For the remaining group, all critical trials were cued recall trials, with half of the trials being tested immediately and half tested after a delay. Again, each serial position was sampled twice per experimental condition. As was the case in Experiments 1-3, the assignment of items to condition and serial position was randomized for each subject, as was the order of the 48 trials.

Procedure. The presentation conditions were much the same as those employed in Experiments 1-3. The six items on each trial were presented visually on a computer screen at a rate of one word per second. The cue either the word "RECALL" for serial recall of the six items in the list or a category label that subsumed one item in the list-appeared immediately or after a filled 2-sec delay. The distractor activity again involved reading aloud two successively presented four-digit strings as they appeared on the screen. Each fourdigit string appeared for $1 \mathrm{sec}$. The subjects had $10 \mathrm{sec}$ to respond to the cue in the appropriate manner before the next trial began.

\section{Results and Discussion}

The data from the present experiment are summarized in Table 3, collapsed across serial position. Each mean represents the likelihood that the target item has been recalled in the case of the cued-recall test or has been recalled in correct serial position in the case of serial recall.

Two ANOVAs were used to provide an initial analysis of the cued recall data. Both involved a $2 \times 2$ design in which retention interval and category dominance were the factors. When retention interval was a betweensubjects factor, there were main effects for retention interval $\left[F(1,36)=13.63, M S_{\mathrm{e}}=0.419\right]$ and dominance $\left[F(1,36)=7.03, M S_{\mathrm{e}}=0.171\right]$, and there was a significant dominance $\times$ retention interval interaction $[F(1,36)$ $\left.=5.47, M S_{\mathrm{e}}=0.171\right]$. The same was true when retention interval was within subjects $\left[F(1,19)=15.55, M S_{\mathrm{e}}=\right.$ $0.020 ; F(1,19)=14.80, M S_{\mathrm{e}}=0.027$; and $F(1,19)=$ $6.35, M S_{\mathrm{e}}=0.024$, for retention interval, dominance, and their interaction, respectively].

Planned comparisons confirmed that category dominance effects were not present on an immediate test when retention interval was between subjects $[F(1,19)=0.10$, $\left.M S_{\mathrm{e}}=0.015\right]$, nor when retention interval was within subjects $\left[F(1,19)=1.48, M S_{\mathrm{e}}=0.020\right]$. In each case, the effect size was also relatively weak (.07 and .26 , respectively). However, high-dominant words were better recalled than were low-dominant words on delayed recall when retention interval was manipulated between subjects $\left[F(1,19)=11.18, M S_{\mathrm{e}}=0.017\right]$ and within subjects $\left[F(1,19)=16.73, M S_{\mathrm{e}}=0.031\right]$. Relatively strong corresponding effect sizes were also obtained (.71 and .87 , respectively).

While there appear to be differences in the levels of performance when retention interval is between subjects rather than within subjects, the similarity of the findings
Table 3

Mean Probability of Recalling the Target Item as a Function of Category Dominance, Type of Test, and Retention Interval

\begin{tabular}{|c|c|c|}
\hline \multirow[b]{2}{*}{ Dominance } & \multicolumn{2}{|c|}{ Retention Interval } \\
\hline & Immediate & Delayed \\
\hline \multicolumn{3}{|c|}{ Experiment 4 (Taxonomic Categories) } \\
\hline \multicolumn{3}{|c|}{$\begin{array}{l}\text { Cued Recall (Retention interval } \\
\text { between subjects) }\end{array}$} \\
\hline High & .83 & .73 \\
\hline Low & $.81(.07)$ & $.60(.71)$ \\
\hline \multicolumn{3}{|c|}{$\begin{array}{l}\text { Cued Recall (Retention interval } \\
\text { within subjects) }\end{array}$} \\
\hline High & .77 & .73 \\
\hline Low & $.71(.26)$ & $.50(.87)$ \\
\hline \multicolumn{3}{|l|}{ Serial Recall } \\
\hline High & .49 & .29 \\
\hline Low & $.50(.12)$ & $.26(.26)$ \\
\hline \multicolumn{3}{|c|}{ Experiment 5 (Rhyme Categories) } \\
\hline \multicolumn{3}{|l|}{ Cued Recall } \\
\hline High & .88 & .76 \\
\hline Low & $.79(.68)$ & $.63(.65)$ \\
\hline \multicolumn{3}{|l|}{ Serial Recall } \\
\hline High & .67 & .39 \\
\hline Low & $.62(.08)$ & $.42(.22)$ \\
\hline
\end{tabular}

Note-Numbers in parentheses reflect the effect size obtained for the comparison of the low-dominant condition with the relevant highdominant condition.

is emphasized when a subjects analysis is done. Thus, on an immediate test when retention interval was between subjects, 8 subjects produced an advantage for highdominant words over low-dominant targets, 3 subjects had tied scores, and 9 subjects produced an advantage for low-dominant words over high-dominant words. When retention interval was within subject, 9 subjects produced a high-dominant advantage, 3 subjects had tied scores, and 8 subjects produced a low-dominant advantage. On a delayed test, the pattern for within and between conditions was identical: 15 subjects produced a high-dominant advantage, 1 subject had a tied score, and 4 subjects produced a low-dominant advantage.

For serial recall, category dominance had no effect upon performance on either an immediate test $[F(1,19)=0.32$, $\left.M S_{\mathrm{e}}=0.009\right]$ or a delayed test $\left[F(1,19)=1.54, M S_{\mathrm{e}}=\right.$ $0.004]$. Effect sizes were also weak (.13 and .27).

The results are entirely consistent with predictions. Category dominance effects, when they appeared, were limited to the cued recall data, confirming the cue-specific nature of these effects. Furthermore, the category dominance effects in cued recall parallel the PI results found by Tehan and Humphreys (1995).

If category dominance and PI effects parallel one another because they both reflect the same underlying cuing and coding processes, the critical test should come when rhyming categories are used (Tehan \& Humphreys, 1995). In the case where PI was manipulated, PI effects were present on an immediate test, as well as on a delayed test. The argument made was that although there was phonemic information present for the target item, that information did not specify the target item alone. If our as- 
sumptions are correct, the same pattern of performance should be observed with category dominance effects. Thus, although phonemic information for the target item might be present, it will not uniquely specify one member out of a group of rhyming competitors. Consequently, category dominance effects would be expected on an immediate test, as well as on a delayed test where the phonemic information is not present. Experiment 5 tested this prediction. Again, the cuing account was tested by having a group of subjects study equivalent trials but respond with serial recall rather than cued recall.

\section{EXPERIMENT 5}

\section{Method}

Subjects. Forty subjects participated for course credit. Twenty subjects were given cued recall trials, and 20 were given serial recall trials.

Materials. The materials used in Experiment 5 were the same as those used in Experiment 3. A word pool composed of a high- and a low-dominant instance from each of 48 different rhyme categories was divided into two subsets, each consisting of 24 high-dominant words and 24 low-dominant words. The high-dominant instance in one set was replaced by the low-dominant instance in the second set, and vice versa, to again control for possible materials effects. These two subsets served as word pools for the creation of the study lists. On each trial, one target word was embedded among five filler items. Twenty-four of the trials involved the high-dominant item, each serial position being sampled four times, twice on an immediate test and twice after a 2 -sec filled retention interval. The same was true of the low-dominant items. As was the case in the previous experiments, the assignment of items to conditions involving serial position and retention interval was randomized for each subject.

\section{Results and Discussion}

The data from the present experiment are summarized in Table 3, again collapsed across serial position. Each mean represents the likelihood that the target item has been recalled in the case of the cued recall test or has been recalled in correct serial position in the case of serial recall.

An initial $2 \times 2$ repeated measures ANOVA resulted in significant main effects for retention interval $[F(1,19)=$ $\left.24.15, M S_{\mathrm{e}}=0.016\right]$ and category dominance $[F(1,19)=$ 13.86, $\left.M S_{\mathrm{e}}=0.018\right]$. However, the interaction between retention interval and dominance was not significant $\left[F(1,19)=1.21, M S_{\mathrm{e}}=0.009\right]$.

Planned comparisons indicated that high-dominant instances of a category were better remembered than were low-dominant items on both an immediate test $[F(1,19)=$ $\left.10.23, M S_{\mathrm{e}}=0.007\right]$ and a delayed test $[F(1,19)=9.46$, $\left.M S_{\mathrm{e}}=0.019\right]$. In each case, relatively strong effect sizes were also present and were just as strong on the immediate test (.68) as on the delayed test (.65). A subjects analysis indicated that, on an immediate test, 14 subjects demonstrated a high-dominant advantage over low-dominant targets, 2 subjects had tied scores, and 4 subjects demonstrated a low-dominant advantage. On a delayed test, 13 subjects produced a high-dominant advantage, 3 subjects produced tied scores, and 4 subjects produced a lowdominant advantage. It would appear that performance on an immediate test is very similar to that on a delayed test and very different from that on an immediate test using taxonomic cues.

For serial recall, category dominance had no effect on performance on either an immediate test $[F(1,19)=$ $\left.2.45, M S_{\mathrm{e}}=0.017\right]$ or a delayed test $[F(1,19)=0.45$, $\left.M S_{\mathrm{e}}=0.037\right]$. Again, effect sizes were weak (.08 and .22 , respectively).

The results again conform to expectations in all respects. Dominance effects are cue dependent in that they are observed only with the appropriate cue. Moreover, dominance effects parallel the PI effects exactly.

\section{GENERAL DISCUSSION}

In the present paper, we have attempted to show that short-term recall is cue dependent by exploring two cuing effects: PI and category dominance. In exploring shortterm PI, we have adopted the Dillon and Bittner (1975) procedure of holding encoding constant and varying the retrieval cues. We have taken conditions where shortterm PI effects are known to occur and, by changing retrieval demands, have produced an attenuation of PI effects. Thus, the results of Experiment 1 indicate that the PI effects that are observed in short-term cued recall are not evident in serial recall. The results of Experiments 2 and 3 suggest that PI effects in cued recall will emerge only if both the target and interfering foil are subsumed by the same cue. Consequently, the first tenet of any theory of short-term PI must indicate that category-specific PI can emerge only if target and interfering items are related to and subsumed by the same cue. The importance of retrieval cues is further reinforced by the finding that category dominance effects parallel short-term PI effects and consequently appear to require the same explanation.

However, before getting too carried away with the cuing notion, it is important to address some methodological issues. Much of our argument rests upon interpreting null results in terms of theoretical factors, and we have assumed that the characteristics of the items from taxonomic and rhyming categories are equivalent, except for category membership. Given that null results can occur for procedural reasons and that many item characteristics can influence recall performance, the issues of power, sensitivity, and item selection become relevant and need to be considered.

It is possible that the lack of any differences involving serial recall might be due to a lack of sensitivity of the task. However, while we recognize the role of output interference, serial recall is sensitive to PI effects. Under experimental conditions similar to those employed in the present experiments, category-specific PI has been observed in serial recall when the lists were categorized (Humphreys \& Tehan, 1992; Tehan \& Humphreys, 1995). Thus, the absence of PI effects in the present experiments cannot be explained solely in terms of serial recall being insensitive to PI effects. We think it is important to reiterate that, given appropriate cues and appropriate coding conditions, PI has been found in all conditions where null results have been reported in this study. 
The notion that our procedures are not sensitive on an immediate test or that there are intrinsic differences between items from taxonomic and rhyme categories also is rejectable. Performance on an immediate test appears to be off ceiling in that in only one experiment was performance above the $90 \%$ level. Moreover, in Experiment 5 where performance levels are among the highest, category dominance effects were observed on an immediate test, and the effect size was marginally stronger than on a delayed test for that material. In other words, it is possible to observe strong effects on an immediate test, and, consequently, differential sensitivity across retention interval does not appear to provide an adequate explanation for the observed patterns of performance.

The difference between rhyme and taxonomic categories does not appear to be due to generalized poor memory for the rhyme materials. Using the part-word cues (Experiments 3 and 5) produces higher levels of recall than does using taxonomic cues. This finding replicates the effects in long-term cued recall tasks where rapid presentation rates are utilized (Nelson \& McEvoy, 1979). In terms of the overall characteristics of the materials, we have attempted to control for the major materials variables that influence recall, such as word frequency, concreteness, and category dominance levels. The only obvious differences between the two sets of materials and their respective fillers was that the items from the rhyme categories and the fillers were all short, one-syllable words, whereas the items and fillers in the taxonomic categories tended to be one or two syllables in length. Given that word length affects immediate serial recall (Baddeley, Thomson, \& Buchanan, 1975), memory for the items from the rhyme categories should be enhanced relative to the items from the taxonomic categories.

The final methodological issue that might be raised involves the power of our experiments. One way to assess power is to consider effect sizes. Table 2 presents the effect size obtained when the interference condition is compared with the no-interference control, and Table 3 presents the effect size for high-dominance versus lowdominance comparisons. While it is generally the case that effect sizes are weaker on an immediate test and stronger on a delayed test, it is possible to observe strong effects on an immediate test (Experiment 5, cued recall) and to observe weak effects on a delayed test (Experiments 2 and 3 ). Thus, retention interval is not the sole determinant of effect size. In fact, when a meta-analysis is carried out by comparing the average effect size in the conditions where we expect to find a difference and the conditions where no difference is expected, the average effect size is .69 and .15 , respectively. This difference is significant $[t(16)=11.55]$. Thus, not only do we have the power to observe moderate to large effect sizes on both immediate and delayed tests, we also demonstrate moderate to large effect sizes under the conditions where we predict cue effects will influence performance and weak effect sizes where cues are not predicted to influence performance.

The reason that power and sensitivity issues are important here is that they impact upon encoding explanations of PI (Gorfein, 1987). That is, if PI effects are due solely to coding effects, then PI should be observable irrespective of the cues used. The only reason this might not occur is if the test was not sensitive enough. Consequently, in asserting that our tests are sensitive, we reject the notion that PI effects are due solely to encoding processes. The encoding explanations have typically emerged from the release-from-PI paradigm, in which all the items on each trial are related (e.g., "three flowers," "three professions," etc.). Under such experimental conditions, it is likely that subjects are encoding category information. In fact, in many experiments, a category label precedes the items (Dillon \& Bittner, 1975; Gardiner et al., 1972). We think that this is less likely to be happening in the present experiments. First, the subjects were encouraged to encode all trials for serial recall, and the presence of serial recall trials reinforced this. If the subjects were encoding for serial order, it is doubtful that they would have encoded information about category membership. Even if the subjects were processing categorical information, only two of the eight items in the list were related, and these were always separated by three intervening items. Furthermore, each target was an instance of multiple categories. Consequently, given the instructions to encode for serial recall and the time constraints involved, it seems unlikely that the specific relationship between the target and foil would have been encoded. Given the experimental procedures used, we think that the present findings are more consistent with a cuing perspective than with an encoding perspective. The present finding that short-term PI effects vary primarily as a function of the retrieval cue is strong evidence for a cuing account of $\mathrm{PI}$ and complements other empirical evidence that supports such a position (Dillon \& Bittner, 1975; Gardiner et al., 1972; O.C. Watkins \& M. J. Watkins, 1975).

While we have tended to concentrate on the PI aspects of the data, the category dominance data are important in their own right. First, few people would argue against the notion that dominance effects are cuing effects. Second, traditional explanations of category dominance effects in cued recall focus entirely upon cue-target strength. From this perspective, there would be very little reason to expect that dominance effects would interact with the type of cue given and retention interval involved. Consideration of the statistical analyses, effect sizes, and subjects analyses lead to the conclusion that performance on an immediate test with taxonomic cues is very different from performance involving ending cues, yet performance is very similar on a delayed test. Clearly, something is interacting with cue-target strength to influence performance on an immediate test.

Since very little research has been done looking at shortterm cued recall of the type described in the present experiments, the explanation for the pattern of dominance effects is somewhat problematic. In providing an explanation for the results, we have focused on the fact that the same materials $\times$ retention interaction is found when PI effects are the dependent measure. It may turn out that PI and dominance effects require different explanations, but, for 
the present, parsimony would suggest that we at least consider the possibility that category dominance and PI effects reflect the same processes. To explain the similarities, we have made two basic assumptions: (1) the representations of more than just the target item are elicited, and (2) phonemic information can provide discriminative power.

Of these two assumptions, the first is probably the more controversial, in that few discussions of category dominance involve the activation of nonpresented instances of a category. The idea that nonpresented items can have an inhibitory effect upon episodic performance is not new. For example, in the part-set cuing paradigm, M. J. Watkins (1975) presented his subjects with lists composed of six instances from six different categories, the instances from all categories being presented in a randomized fashion. At test, subjects were given the names of the categories and zero, two, or four instances from each category. The instances chosen were either list items or items from the category that were not on the study list. The typical inhibitory part-set cuing effect was observed, in that the probability of recalling the noncued items on the study list decreased as the number of instances presented as cues increased. For present purposes, the important finding was that the strength of the inhibitory effect was just as strong for nonstudied instances as for studied instances. In other words, items from a particular category inhibited recall performance on a subsequent cued recall test, even though these items had not been studied. Of course, one important difference between the present experiments and the part-set cuing task is that the nonstudied items in the part-set task do have an episodic component in that they were presented at test. We are assuming that nonpresented items have an influence on performance even though there is no episodic component.

Generally speaking, the idea of inhibitory effects due to semantic memory factors is also not new. The "fan" effects that Anderson (1974; Lewis \& Anderson, 1976) has postulated in his descriptions of interference effects in long-term retrieval is one such example. However, in spite of demonstrations such as Anderson's, most of the current models of episodic memory make very little provision for semantic memory effects in general, and, with the exception of the connectionist model of Chappell and Humphreys (1994) and the PIER model of Nelson et al. (1992), none specify the simultaneous activation of all members of a category in cued recall with a category cue. The work of Nelson and his colleagues is particularly relevant in that they have provided the most detailed examination of the cued recall task and have convincingly demonstrated that cued recall with an extralist cue is determined by three independent factors: cue set size, target set size, and cue-target strength. Both the cue set size and target set size effects reflect the influence of what Nelson et al. (1992) call preexisting implicit memoriesthat is, associatively related items that are not episodically present in the cued recall task.

The Chappell and Humphreys (1994) connectionist model also allows for the effects of preexisting memo- ries. The concept of an intersection (Humphreys, Wiles, \& Bain, 1993) is an essential component of the retrieval process in the Chappell and Humphreys model. In the case of cued recall with an extralist cue, they assume that all associates of a cue are activated and all other words are suppressed. Likewise, all items associated with a context cue (all items in the present list) are activated and all other words are suppressed. When the two sets are intersected, only those items that are common to both sets survive (i.e., the item from the list that was an instance of the category). However, preexisting memories can interfere with list memories if there is some degree of overlap in the representations of preexisting and episodic items. The model has been successful not only with cued recall but also in accounting for much of the recognition data, similarity effects, the dissociation between recognition and frequency judgments, and retroactive interference effects.

Consequently, given Nelson's work in which preexisting memories play an integral role in cued recall and Chappell and Humphrey's successful treatment of quite diverse memory phenomena with a model that incorporates both preexisting and episodic memories, we think that our assumption that the representation of all members of a category are activated by a retrieval cue in short-term cued recall is reasonable.

Our assumptions concerning the role of phonemic codes in the task are probably less controversial. The role of phonemic codes in short-term memory has been most evident in immediate serial recall. Baddeley (1986), in developing the concept of the articulatory loop, has demonstrated the way in which phonemic codes interact with other variables in immediate serial recall. The influence of these codes in the Brown-Peterson task has also been established, and the transience of these codes has likewise been well documented (Conrad, 1967; Estes, 1973; Nairne, 1988, 1990; Tell, 1972). If our assumption is correct, PI and category dominance effects indicate that phonemic codes may well have a generalized impact upon short-term episodic memory performance. In any event, the present results provide a challenge to those models of short-term memory that are based upon the immediate serial recall task. Phonemic coding effects appear to extend beyond the phonemic similarity effect and beyond immediate serial recall.

In conclusion, the finding that short-term PI effects and short-term category dominance effects parallel one another is a significant finding. These results, together with the results of the first three experiments reported here, strongly implicate the role of cues in short-term memory performance. The fact that both PI and category dominance appear to be affected by the presence or absence of phonemic information again confirms the generally recognized importance of phonemic codes in short-term memory. Reviewing a recent symposium on short-term memory, Craik (1991) addressed the issue of how shortterm memory could, at the same time, look very much like long-term memory and very dissimilar to it: 
One way in which short-term and long-term memory could "look the same" would be if the principles that govern performance were identical at all retention intervals ... short-term and long-term retention could still "look different" because of a change in the relative usefulness or salience of the underlying memory codes. (p. 201)

We think that the PI and category dominance data support Craik's observations. If it is assumed that retrieval is cue based at both short and long retention intervals, but that phonemic codes tend to be particularly salient at short retention intervals, then quite disparate memory phenomena, such as immediate serial recall, proactive interference, and category dominance, can be related to one another in a principled way.

\section{REFERENCES}

ANDERSON, J. R. (1974). Retrieval of propositional information from long-term memory. Cognitive Psychology, 6, 451-474.

BADDELEY, A. D. (1986). Working memory. Oxford: Oxford University Press.

Baddeley, A. D., Thomson, N., \& Buchanan, M. (1975). Word length and the structure of short-term memory. Journal of Verbal Learning \& Verbal Behavior, 14, 575-589.

Brown, J. A. (1958). Some tests of the decay theory of immediate memory. Quarterly Journal of Experimental Psychology, 10, 12-21.

Chappell, M., \& Humphreys, M. S. (1994). An auto-associative neural network for sparse representations: Analysis and application to modeis of recognition and cued recall. Psychological Review, 101, 103-128.

CONRAD, R. (1967). Interference or decay over short retention intervals. Journal of Verbal Learning \& Verbal Behavior, 6, 49-54.

Craik, F. I. M. (1991). Peace pipes around the TODAM pole: A puff for short-term memory. In W. E. Hockley \& S. Lewandowsky (Eds.) Re lating theory and data: Essays on human memory in honor of Bennet B. Murdock (pp. 195-203). Hillsdale NJ: Erlbaum.

Crowder, R. G. (1989). Modularity and dissociations in memory systems. In H. L. Roediger III \& F. I. M. Craik (Eds.), Varieties of memory and consciousness: Essays in honor of Endel Tulving (pp. 271. 294). Hillsdale, NJ: Erlbaum.

DEMPSTER, F. N., \& COONEY, J. B. (1982). Individual differences in digit span, susceptibility to proactive interference, and aptitude/achievement test scores. Intelligence, 6, 399-416.

Dillon, R. F., \& BitTNER, L. A. (1975). Analysis of retrieval cues and release from proactive inhibition. Journal of Verbal Learning $\&$ Verbal Behavior, 14, 616-622.

EsTES, W. K. (1972). An associative basis for coding and organization in memory. In A. W. Melton \& E. Martin (Eds.), Coding processes in human memory (pp. 161-190). Washington, DC: Winston.

Estes, W. K. (1973). Phonemic encoding and rehearsal in short-term memory for letter strings. Journal of Verbal Learning \& Verbal Behavior, 12, 360-372.

ESTES, W. K. (1991). On types of item coding and source of recall in short-term memory. In W. E. Hockley \& S. Lewandowsky (Eds.), Relating theory and data: Essays on human memoiy in honor of Bennet B. Murdock (pp. 155-173). Hillsdale, NJ: Erlbaum.

Gardiner, J. M., Craik, F. I. M., \& Birtwistle, J. (1972). Retrieval cues and release from proactive inhibition. Journal of Verbal Learn ing \& Verbal Behavior, 11, 778-783.

GoRFEIN, D. S. (1987). Explaining context effects on short-term memory. In D. S. Gorfein \& R. R. Hoffman (Eds.), Memory and learning: The Ebbinghaus Centennial Conference (pp. 153-172). Hillsdale, NJ: Erlbaum.

Halford, G. S., Maybery, M. T., \& Bain, J. D. (1988). Set-size effects in primary memory: An age-related capacity limitation? Memory \& Cognition, 16, 480-487.

HumphrEYs, M. S., \& TEHAN, G. (1992). A simultaneous examination of recency and cuing effects. In A. Healy, S. Kosslyn, \& R. M. Shiff- rin (Eds.), From learning theory to cognitive processes: Essays in honor of William K. Estes (Vol. 2, pp. 143-159). Hillsdale, NJ: Erlbaum.

HuMPhreYs, M. S., Wiles, J., \& Bain, J. D. (1993). Memory retrieval with two cues: Think of intersecting sets. In D. E. Meyer \& S. Kornblum (Eds.), Attention and performance XIV: Synergies in experimental psychology, artificial intelligence and cognitive neuropsychology-A Silver Jubilee (pp. 489-508). Cambridge, MA: MIT Press.

Johnson, G. J. (1991). A distinctiveness model of serial learning. Psychological Review, 98, 204-217.

JoNES, D. M. (1993). Objects, streams and threads of auditory attention. In A. D. Baddeley \& L. Weiskrantz (Eds.), Attention: Selection, awareness and control (pp. 87-104), Oxford: Oxford University Press.

KePPEL, G., \& UNDERWOOD, B. J. (1962). Proactive inhibition in shortterm retention of single items. Journal of Verbal Learning \& Verbal Behavior, 1, 153-161.

Kučera, H., \& Francis, W. N. (1967). Computational analysis of present-day American English. Providence, RI: Brown University Press.

LEE, C. L., \& EsTES, W. K. (1977). Order and position in primary memory for letter strings. Journal of Verbal Learning \& Verbal Behavior, 16, 395-418.

LEWANDOWSKY, S., \& MURDOCK, B. B. (1989). Memory for serial order. Psychological Review, 96, 25-57.

LEWIS, C. H., \& ANDERSON, J. R. (1976). Interference with real world knowledge. Cognitive Psychology, 7, 311-355.

McEvoy, C. L., \& Nelson, D. L. (1982), Category name and instance norms for 106 categories of various sizes. American Journal of Psychology, 95, 581-634.

MCNiCOL, D. (1978). Initial codes for order in memory. Quarterly Journal of Experimental Psychology, 30, 681-691.

NAIRNE, J. S. (1988). A framework for interpreting recency effects in immediate serial recall. Memory \& Cognition, 16, 343-352.

NAIRNE, J. S. (1990). A feature model of immediate memory. Memory \& Cognition, 18, 251-269.

NeLSON, D. L. (1989). Implicitly activated knowledge and memory. In C. Izawa (Ed.), Current issues in cognitive processes: The Tulane Flowerree Symposium on Cognition (pp. 369-387). Hillsdale, NJ: Erlbaum.

Nelson, D. L., \& FriedRICH, M. A. (1980). Encoding and cuing sounds and senses. Journal of Experimental Psychology: Human Learning \& Memory, 6, 717-731.

Nelson, D. L., \& McEvoy, C. L. (1979). Encoding context and set size. Journal of Experimental Psychology: Human Learning \& Memory, 5, 292-314.

Nelson, D. L., Schreiber, T. A., \& McEvoy, C. L. (1992). Processing implicit and explicit representations. Psychological Review, 99, 322-348.

Peterson, L. R., \& Peterson, M. J. (1959). Short-term retention of individual items. Journal of Experimental Psychology, 58, 193-198.

SHIFFRIN, R. M., \& COOK, J. R. (1978). Short-term forgetting of item and order information. Journal of Verbal Learning \& Verbal Behavior, 17, 189-218.

Tehan, G., \& Humphreys, M. S. (1995). Transient phonemic codes and immunity to proactive interference. Memory \& Cognition, 23, 181-191.

TelL, P. M. (1972). The role of certain acoustic and semantic factors at short and long retention intervals. Journal of Verbal Learning \& Verbal Behavior, 11, 555-564.

Walling, J. R., McEvoy, C. L., Oth, J. E., \& Nelson, D. L. (1984). The University of South Florida rhyme category norms. Unpublished manuscript, University of South Florida, Tampa.

WatKINS, M. J. (1975). Inhibition in recall with extralist "cues." Journal of Verbal Learning \& Verbal Behavior, 14, 294-303.

WATKINS, M. J. (1981). Engrams as cuegrams and forgetting as cue overload: A cueing approach to the structure of memory. In C. R. Puff (Ed.), The structure of memory (pp. 347-372) New York: Academic Press.

WATKINS, O. C., \& WATKINS, M. J. (1975). Build-up of proactive inhibition as a cue overload effect. Journal of Experimental Psychology: Human Learning \& Memory, 104, 442-452.

WICKENS, D. D. (1972). Characteristics of word encoding. In A. W. Melton \& E. Martin (Eds.), Coding processes in human memory (pp. 191-215). Washington, DC: Winston.

Wickens, D. D., Born, G. D., \& Allen, C. K. (1963). Proactive inhibition and item similarity in short-term memory. Journal of Verbal Learning \& Verbal Behavior, 2, 440-445. 
Wickens, D. D., Moody, M. J., \& Dow, R. (1981). The nature of timing of the retrieval process and of interference effects. Journal of Experimental Psychology: General, 110, 1-20.

\section{NOTES}

1. It is important to note that here we are talking about category-specific PI and not the experiment-wide PI that Keppel and Underwood (1962) report. To the best of our knowledge, no one has systematically studied this type of $\mathrm{PI}$ in serial recall. In looking at the data from several experiments in our lab, it would appear that experiment-wide PI effects mirror category-specific $\mathrm{PI}$ in that the effects are more readily seen after a brief retention interval than on an immediate test.
2. One methodological explanation for the absence of interference effects might stem from the fact that only the second and third serial positions were cued. If subjects were aware of this, they might be able to restrict their answers and thus know, with some certainty, which items to focus upon. While this may occur, it does not explain why subjects do produce PI effects in the different category condition, nor does it provide an adequate explanation of the PI effects on an immediate test that were present in the Tehan and Humphreys (1995) experiments.

(Manuscript received May 8, 1995; revision accepted for publication July 24,1995 .) 